\title{
The investigation of relationships among sprint and jump performance with velocity parameters during propulsive phase of full back squat exercise
}

\author{
Ibrahim CAN ${ }^{1}$, Hamit CIHAN ${ }^{2}$, Erdal ARI ${ }^{3}$ \\ ${ }^{1}$ School of Physical Education and Sports, Gumushane University, Gumushane, Turkey. \\ ${ }^{2}$ School of Physical Education and Sports, Karadeniz Technical University, Trabzon, Turkey. \\ ${ }_{3}^{3}$ School of Physical Education and Sports, Ordu University, Ordu, Turkey. \\ This study is summerized from a part of Ibrahim Can's doctoral thesis. \\ Adress correspondence to I. Can, ibrahimcan@gumushane.edu.tr
}

\begin{abstract}
The basic purpose of this study was to investigate of the relationships with sprint and jump performance of velocity parameters during propulsive phase of full back squat exercise and to determine which variable was associated with which loading loading. For this purpose, thirty-two men amateur athletes (age: $20.4 \pm 1.98$ years; height: $179.3 \pm 7.23 \mathrm{~cm}$; weight: 73.5 $\pm 9.85 \mathrm{~kg}$ ) who actively involved in sports and have a basic level of force participated in voluntarily to this study. In the study, one repetition maximum (1RM) full squat (SQ) strength test, vertical jump test, 5 meters and 30 meters sprint test were applied. The descriptive statistics and Pearson correlation analysis was used for statistical evaluation of datas. According to analysis results; it was obtained that mean velocity (MV), mean propulsive velocity (MPV) and peak velocity (PV) values during propulsive phase of full back squat exercise performed in different loads were decreased in parallel with load increase. In addition, it was obtained that there was no statistically a significant relationships between 5 meters sprint times and vertical jump performance with MV, MPV and PV values during propulsive phase of full back SQ exercise performed at different loads of $1 R M(p>0.05)$. Conversely, it was obtained that there was a mean level, negative and statistically significant relationship between 30 meters sprint times with MV during propulsive phase of full back SQ movement performed at $20 \%$ and $\% 90$ of $1 \mathrm{RM}$ load values $(\mathrm{r}=-.412 ; \mathrm{r}=-.399, \mathrm{p}<0.05$, respectively) and PV values obtained at $40 \%$ and $60 \%$ of $1 \mathrm{RM}$ load values $(\mathrm{r}=-.402 ; \mathrm{r}=-.370, \mathrm{p}<0.05$, respectively). Consequently, it was suggested that movement velocity is not an important component for performance parameters as 5 meter sprint and jumping height.
\end{abstract}

Key Words: Full back squat, propulsive phase, sprint, velocity, vertical jump.

\section{INTRODUCTION}

The kinematics and kinetics associated with resistance training are believed to be critical stimuli for neuromuscular adaptations to occur (11). Stimulated muscle, applies force to tendons that supplies a transfer to skeleton structure trying to contract and natural resistances encountered during the movement of a muscle determines conclusion movement (1). That is, muscle has a feature that arranges opposite force can withstand to itself was applied resistance during shortening of the length and this feature which distinguishes muscle from a simple elastic object was based on constantly arrange against an external resistance of velocity produced by muscle contraction system (15).

One of the main problems that strength and conditioning coaches encounter is how to objectively quantify and monitor the actual training load undertaken by athletes in order to maximize. Several acute training variables have been identified for resistance training programme design (exercise type and order, intensity or load, number of repetitions and sets, rest between sets) (23). Manipulating these variables shapes the type and magnitude of physiological responses and, ultimately, it reveals the adaptations to strength training $(7,18,39)$.

Velocity which is known as a vectored quantity is the time wise ratio of change in positions (41) and is one of the parameters that is used for digitizing the volume of exercises in resistance training $(10,18$, $21,31)$. Therefore, it was suggested that movement velocity is a basic parameter to regulate the effects of training $(18,19,20,28,29,34,36)$. That is in order to follow the intensity of an exercise, movement velocity is a variable to be more attracted yet 
although some authors have noticed (20, 31), movement velocity was mentioned vaguely in many studies. The actual velocity performed in each repetition could perhaps be the best reference to gauge the real effort which is being incurred by the athletes. This situation may create a better effort level called as a velocity based resistance training which is more accurate and rational training paradigm (18). Because the intensity of training is accepted as the most important stimuli related to the changes in velocity levels (22) and generally associated with (1RM \%) relative load (16).

In a study completed by Gonzales-Badillo and Sancez-Medina (18), it was obtained that a very close relationship $(\mathrm{r} 2=0.98)$ between relative load $(1 \mathrm{RM}$ $\%)$ and mean propulsive velocity (MPV). Similar results were obtained by different researchers. Sanchez-Medina et al. (35) obtained that there are very close relationship ( $\mathrm{r} 2=0.96$ ) between $1 \mathrm{RM} \%$ and MPV in the full back squat exercise. That is, the higher the velocity achieved against a given load (absolute), the greater the intensity and this will influence the training effect. Therefore, movement velocity is a key ingredient of training intensity (19) and it was suggested that strength training is a very effective criteria for intensity measurements $(18,21$, 31).

Sprint is an ability to run at maximal or close maximal velocity in a shortest time period (3) and most of them are significant determinant for an achievement in sports (5). Therefore, sprint ability is a complex ability that requires proper motor coordination between joints and muscles (13). Sprint ability over very short distances (5 or 10 meters) is considered by many researchers and practitioners to require specific strength qualities and running technique, and generally is accepted that shorter sprints require a greater contribution of concentric muscle contractions and knee extensor activity (26).

Sprint and jump performance are accepted as the most significant components of many sports like soccer, basketball and handball and these components are quite effective for achievement in this sports. So, most of the training methods are applied to increase the strength and power in sports by developing the physical performance and in this way the performance of sprint and jump in team sports $(17,38)$. Considering studies in literature, it was seen that there was no studies examining the relationship between vertical jump performance and 5 - 30 meters sprint durations with velocity parameters during propulsive phase (concentric stage) of full back squat movement. In literature, generally, it can be seen that examining relationships among sprint duration and jump performance with 1RM strength values were studied. Therefore, in this study was aimed to find out the relationship between $5-30 \mathrm{~m}$ sprint duration and jump performance with velocity parameters during propulsive phase of full back SQ movement and to determine which variable was associated with which loading intensity. It was thought that these results obtained from this study will contribute to trainers, conditioners and sports science literature, while preparing of training programmes and jump exercises and to increase sprint duration of athletes.

\section{MATERIAL \& METHOD}

\section{Subjects}

Thirty-two men amateur athletes (age: $20.4 \pm$ 1.98 years; height: $179.3 \pm 7.23 \mathrm{~cm}$; weight: $73.5 \pm 9.85$ $\mathrm{kg}$ ) who actively involved in sports and have a basic level of force participated in voluntarily to this study.

\section{Data Collection Tools}

In this study, subject's height and weight values were determined using a Seca 769 electronic measurement device (Seca Corporation, Hamburg, Germany). One repetition maximal (1RM) strength values in full back squat (SQ) exercise of subjects were obtained using smith machine (Esjim, Eskisehir, Turkey) which a stable vertical plane. Free weights $(1,1.25,2.5,5,10,15$ and $20 \mathrm{~kg})$ which controlled weights with an electronic device was used for determining 1RM strength values in the full back SQ exercise using smith machine.

T-Force device (Ergotech, Murcia, Spain) was used for determining velocity parameters during propulsive phase of full back SQ exercise that different loads were implemented (figure 1). This system is a dynamic measurement system and technically, it can be considered as an isoinertial speedometer since it directly measures the velocity at which loads are lifted. Its use is particularly suitable for typical weight-lifting exercises or any resistance training exercise where it is necessary to overcome, against gravity, a load (constant mass) that moves along the vertical axis. The system consists of an electromechanical equipment (velocity sensor and interface; figure 1a, 1b), a hook attached to weight training barbell (figure 1c), and a computer program (T-Force software; figure 1d) governing the hardware. It is the sensor that 
measures the velocity of moving loads. The transducer is usually placed on the floor and inside the aluminum housing, a high precision tachogenerator measures how fast the 2 meter cable extends or retracts. That is, the sensor provides a voltage proportional to the velocity with which the cable is moving. The communications interface consists of an electronic data acquisition board equipped with a 14-bit resolution converted. The connection to the computer is via a USB port, allowing a very fast and safe data transfer. The sampling frequency at which data are acquired is fixed at $1.000 \mathrm{~Hz}$, that is you get a instantaneous velocity daya every millisecond. The software is automatically calculates the relevant kinetic and kinematic parameters as force, power and velocity of every repetition in resistance training and displays them numerically and graphically on screen. In addition, the software provides auditory feedback and stores data on disk for analysis (18, 19, 34, 35, $36,37)$.

5 and 30 meters sprint durations of subjects were obtained using a portable photocell system
(Newtest Powertimer Model 300s, Oy, Finland). A tape measure was used for jump height.

\section{Data Collection Process}

Data collection process was completed in three different periods in this study. First period, 1RM values in the full SQ exercise and physical characteristics of subjects were determined and weights which corresponding different percentages $(20,30,40,50,60,70,80,90$, and $100 \%)$ of $1 \mathrm{RM}$ were recorded calculating.

In second period, full back SQ exercise was performed at weights calculated previously in different percentages of 1RM. Propulsive phases during full back SQ exercise of subjects in the applied loads were obtained as mean velocity (MV), mean propulsive velocity (MPV) and peak velocity (PV). In third and final period, 5 - 30 meters sprint and vertical jump tests were applied. Information about how data collected during the study is described as detail in case of subtitles.
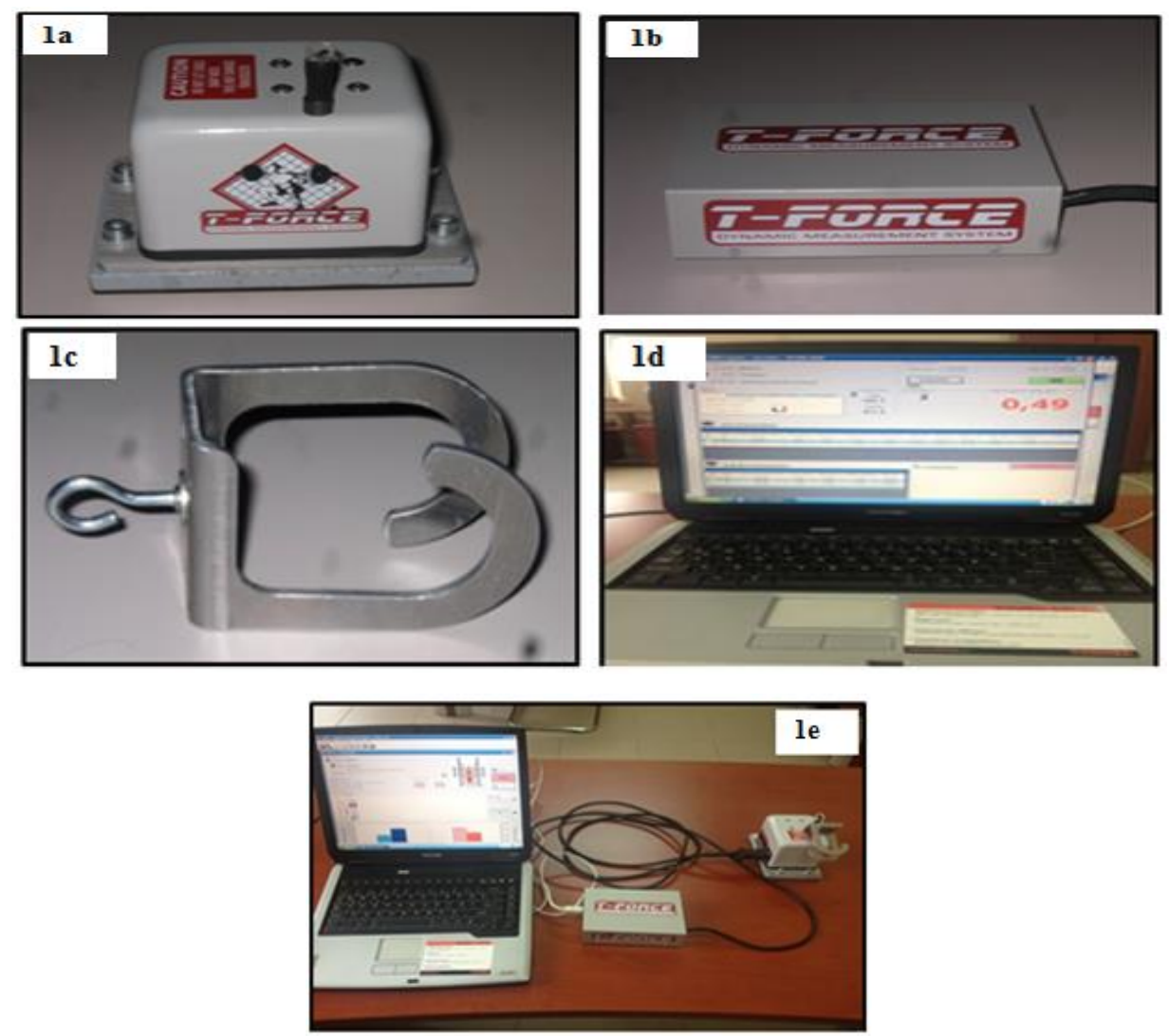

Figure 1. T-Force dynamic measurement system: (1a) velocity sensor, (1b) interface, (1c) a hook attached to weight training barbell, (1d) T-Force software, (1e) Set up of the system. 


\section{One Repetition Maximal Strength Test}

In this study, 1RM strength values in the full back SQ exercise of subjects were obtained with test procedure designed by Beachle et al., (6). Processes applied in this test procedure were broadly explained as below.

1. After a 10 minutes general warm-up, the subjects warms up by performing repetitions with a load that allows 5 to 10 repetitions,

2. One minute rest was given,

3. Estimate a warm-up load that allows the subject to complete three to five repetitions by adding a load between 14 to $18 \mathrm{~kg}$, or 10 to $20 \%$, to the load used in step 1 ,

4. Two minutes rest was given,

5. Estimate a near maximal load that will allow the subject to complete two or three repetitions by adding a load between 14 to $18 \mathrm{~kg}$, or 10 to $20 \%$, to the load used in step 3.

6. Two to four minutes rest was given,

7. The subject performs a 1RM attempt by increasing the load used in step 5 by 14 to $18 \mathrm{~kg}$, or 10 to $20 \%$,

8. Two to four minutes rest was given,

9. If subject succeed in lifting the load in step 7 , the load has been resumed increasing in proper proportions. But, if the subject fails the $1 \mathrm{RM}$ attempt, decrease the load by removing 7 to $9 \mathrm{~kg}$, or 5 to $10 \%$, and have the subject perform one repetition,

10. Two to four minutes rest was given,

11. Continue increasing or decreasing the load until the subject can complete one repetition with appropriate technique. The subject's 1RM value was maximally obtained within five attempts.

\section{Full Back Squat Exercise Procedure}

After 1RM strength values of subjects who participated in study was obtained, lifting measurements in different percentages of $1 \mathrm{RM}$ was carried out in a fitness center (figure 2). Full back squat exercise was performed using a procedure which designed by Earle \& Beachle (14). In this procedure, the subject grasped the barbell with a closed, pronated grip slightly wider than shoulder width and the barbell was placed above the posterior deltoids (high bar position). The feet should be slightly wider than shoulder width and indicated slightly outward when the subject begins the descent. The subject reached the lowest point in the descent when the top of the thighs are parallel to the ground, and the barbell lifted in a continuously motion without assistance. For safety, at least two observers were stood on either side of the barbell and followed the bar during the descent and ascent. It was emphasized that subjects should breathe out when lifting the barbell and breathes in when lowering the barbell during implementing of the full back SQ exercise. During lifting to perform in the full back SQ exercise, subjects were performed to three repetitions for light loads, and two repetitions for middle loads and the best values were recorded for statistical analysis. Also, one repetition was performed for heavy loads. For rest times, it was given two to three minutes for light and middle loads, and three to five minutes for heavy loads.

\section{Sprint Tests}

After general a warm up activity of ten minutes, athletes were applied the two times 5 and $30 \mathrm{~m}$ sprint tests from a statically position (behind 0 meter of first photocell sensor) with three minutes rest period to ensure a full recovery on the athletics running track. The best 5 and $30 \mathrm{~m}$ sprint durations of athletes were reported for statistical analysis.

\section{Vertical Jump Test}

After general a warm up activity of ten minutes, athletes were applied the vertical jump test in a indoor sports hall. Firstly, in front of the test platform was determined to standard arm length of athletes and then it was dictated that jumps as high as possible, but should fall on the ground without bending his knees after the jump. The end of the test, it was determined to difference between player's arm length with vertical jump height and vertical jump height was recorded as centimeters. Athletes were performed two times vertical jump tests by giving adequate rest periods and the best vertical jump height were reported for statistical analysis.

\section{Statistical Analysis}

In this study, to statistical analysis of data was used the SPSS 16.0 statistical package program. Subject's physical, performance values and velocity parameter values during propulsive phase of full squat movement performed in different loads were determined as mean, standard deviation, minimal and maximal with descriptive statistics. Pearson correlation analysis technique was used to determine correlations between 5 - 30 meters sprint durations and vertical jump distance with velocity 
parameters. The significance level for all statistical analysis was accepted as $\mathrm{p}<.05$.

\section{RESULTS}

The descriptive statistical values regarding to physical and performance property of subjects were seen Table 1.

The descriptive statistical values regarding to velocity parameters during propulsive phase of full squat exercise performed at different loads by subjects joining to study were seen at Table 2 . According to descriptive statistical values, MV, MPV and PV values of SQ movements performed at different loads reduced in parallel with increase of load. Also, maximal and lowest velocities for $\mathrm{MV}$, MPV and PV parameters were determined at $20 \%$ and $100 \%$ of $1 \mathrm{RM}$ load (maximal velocities: 1,164

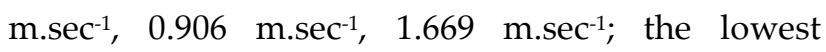
velocities: $0.169 \mathrm{~m} . \mathrm{sec}^{-1} ; 0.147 \mathrm{~m} . \mathrm{sec}^{-1} ; 0.585 \mathrm{~m} . \mathrm{sec}^{-1}$, respectively).

The Pearson correlation results regarding to relationship among velocity parameters (MV,MPV, PV) during propulsive phase of full squat movement performed at different loads with 5 and 30 meters sprint durations and jump performance values of subjects were seen at table 3,4 and 5 .
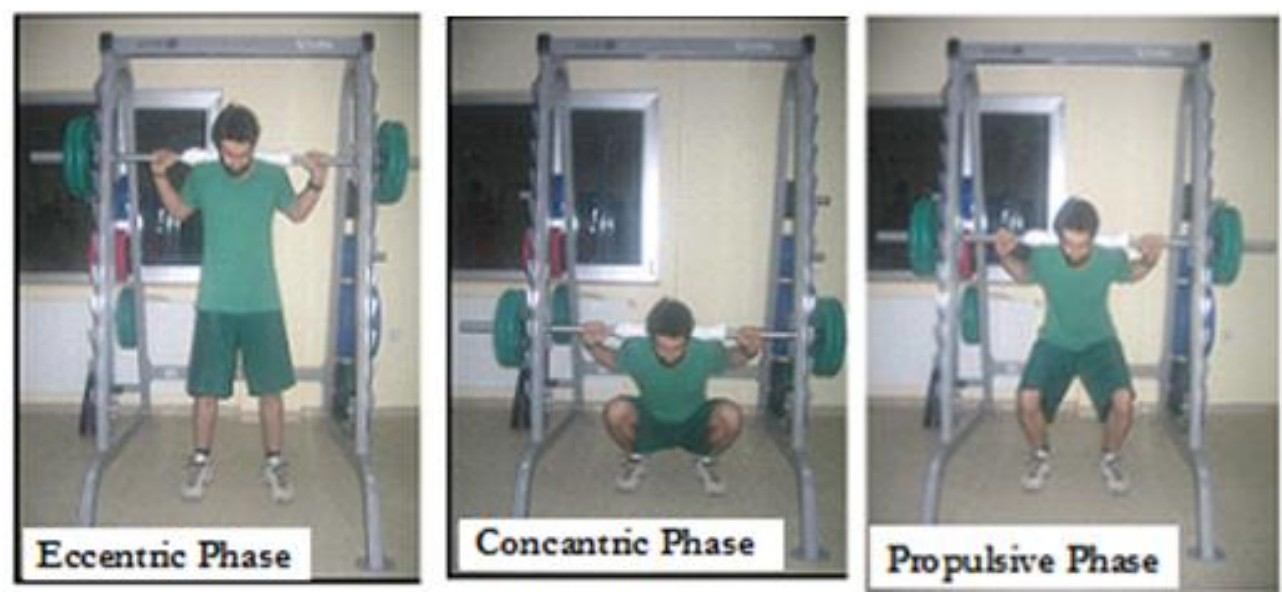

Figure 2. Implementation of full back squat exercise

Table 1. Physical and performance values of subjects.

\begin{tabular}{lccccc}
\hline Variables & $\mathrm{n}$ & Mean & SD & Minimal & Maximal \\
\hline & & & & & \\
Age (years) & 32 & 20.4 & \pm 1.98 & 18 & 24 \\
Height (cm) & 32 & 179.3 & \pm 7.23 & 164 & 191.5 \\
Weight (kg) & 32 & 73.5 & \pm 9.85 & 54.7 & 99.7 \\
5 meter sprint duration (sec) & 32 & 1.11 & \pm 0.73 & 1.01 & 1.29 \\
30 meter sprint duration (sec) & 32 & 4.39 & \pm 0.18 & 3.97 & 4.77 \\
Vertical jump height (cm) & 32 & 50.25 & \pm 7.50 & 34 & 69 \\
1RM strength (kg) & 32 & 101.0 & \pm 18.7 & 70 & 150 \\
& & & & & \\
\hline
\end{tabular}

Table 2. Velocity values during the propulsive phase in full back squat exercise.

\begin{tabular}{ccccc}
\hline 1RM Load & \multicolumn{3}{c}{ Velocity Parameters $\left(\mathrm{m} / \mathrm{sec}^{-1}\right)$} \\
\hline$(\%)$ & $\mathrm{n}$ & $\mathrm{MV}$ & $\mathrm{MPV}$ & $\mathrm{PV}$ \\
\hline & & & & \\
32 & 32 & $1.164 \pm 0.200$ & $0.906 \pm 0.080$ & $1.669 \pm 0.163$ \\
40 & 32 & $0.1 .101 \pm 0.219$ & $0.757 \pm 0.084$ & $1.585 \pm 0.183$ \\
50 & 32 & $0.710 \pm 0.172$ & $0.635 \pm 0.083$ & $1.464 \pm 0.145$ \\
60 & 32 & $0.571 \pm 0.133$ & $0.524 \pm 0.087$ & $1.299 \pm 0.164$ \\
70 & 32 & $0.404 \pm 0.106$ & $0.396 \pm 0.054$ & $1.117 \pm 0.190$ \\
80 & 32 & $0.266 \pm 0.072$ & $0.305 \pm 0.059$ & $0.969 \pm 0.205$ \\
90 & 32 & $0.217 \pm 0.423$ & $0.218 \pm 0.037$ & $0.767 \pm 0.218$ \\
100 & 32 & $0.169 \pm 0.040$ & $0.147 \pm 0.285$ & $0.716 \pm 0.179$ \\
& & & $0.585 \pm 0.207$
\end{tabular}

MV: Mean Velocity; MPV: Mean Propulsive Velocity; PV: Peak Velocity 
Table 3. Relationship between 5 meters sprint duration and velocity parameters in the propulsive phase of full back squat exercise performed in different loads.

\begin{tabular}{|c|c|c|c|c|c|c|c|}
\hline \multirow{2}{*}{ 1RM Load (\%) } & \multirow{2}{*}{$\mathrm{n}$} & \multicolumn{2}{|c|}{ MV - 5 m Sprint } & \multicolumn{2}{|c|}{ MPV - $5 \mathrm{~m}$ Sprint } & \multicolumn{2}{|c|}{ PV - 5 m Sprint } \\
\hline & & $\mathrm{r}$ & $\mathrm{p}$ & $\mathrm{r}$ & $\mathrm{p}$ & $\mathrm{r}$ & $\mathrm{p}$ \\
\hline 20 & 32 & -.048 & .794 & -.312 & .082 & .209 & .251 \\
\hline 30 & 32 & -.034 & .852 & -.304 & .091 & .035 & .851 \\
\hline 40 & 32 & .061 & .739 & .112 & .543 & -.033 & .858 \\
\hline 50 & 32 & .186 & .307 & .239 & .188 & .094 & .608 \\
\hline 60 & 32 & -.056 & .761 & .171 & .350 & -.237 & .192 \\
\hline 70 & 32 & .128 & .484 & .168 & .357 & .101 & .583 \\
\hline 80 & 32 & .143 & .435 & .086 & .640 & .086 & .641 \\
\hline 90 & 32 & -.224 & .218 & .063 & .731 & .065 & .725 \\
\hline 100 & 32 & .053 & .773 & -.023 & .899 & .153 & .403 \\
\hline
\end{tabular}

Table 4. Relationship between 30 meters sprint duration and velocity parameters in the propulsive phase of full back squat exercise performed in different loads.

\begin{tabular}{|c|c|c|c|c|c|c|c|}
\hline \multirow{2}{*}{$\begin{array}{c}\text { 1RM Load } \\
(\%)\end{array}$} & \multirow[b]{2}{*}{$\mathrm{n}$} & \multicolumn{2}{|c|}{ MV - $30 \mathrm{~m}$ Sprint } & \multicolumn{2}{|c|}{ MPV - $30 \mathrm{~m}$ Sprint } & \multicolumn{2}{|c|}{ PV - 30 m Sprint } \\
\hline & & $\mathrm{r}$ & $p$ & $\mathrm{r}$ & $p$ & $\mathrm{r}$ & $\mathrm{p}$ \\
\hline 30 & 32 & -.217 & .233 & -.124 & .500 & -.129 & .481 \\
\hline 40 & 32 & -.318 & .077 & .217 & .233 & $-.402 *$ & .023 \\
\hline 50 & 32 & -.167 & .362 & .069 & .707 & -.251 & .166 \\
\hline 70 & 32 & .012 & .949 & .188 & .303 & -.091 & .620 \\
\hline 80 & 32 & .237 & .192 & .189 & .300 & .153 & .403 \\
\hline 90 & 32 & $-.399 *$ & .024 & .151 & .409 & -.326 & .068 \\
\hline 100 & 32 & -.311 & .083 & -.211 & .248 & -.305 & .090 \\
\hline
\end{tabular}

Table 5. Relationship between vertical jump performance and velocity parameters in the propulsive phase of full back squat exercise performed in different loads.

\begin{tabular}{|c|c|c|c|c|c|c|c|}
\hline \multirow{2}{*}{$\begin{array}{c}\text { 1RM Load } \\
(\%)\end{array}$} & \multirow[b]{2}{*}{$\mathrm{n}$} & \multicolumn{2}{|c|}{ MV - Vertical Jump } & \multicolumn{2}{|c|}{ MPV - Vertical Jump } & \multicolumn{2}{|c|}{ PV - Vertical Jump } \\
\hline & & $\mathrm{r}$ & $\mathrm{p}$ & $\mathrm{r}$ & $\mathrm{p}$ & $\mathrm{r}$ & $\mathrm{p}$ \\
\hline 20 & 32 & .172 & .345 & -.047 & .797 & .120 & .514 \\
\hline 30 & 32 & .044 & .811 & .013 & .944 & .178 & .328 \\
\hline 40 & 32 & .192 & .293 & -.254 & .161 & .255 & .158 \\
\hline 50 & 32 & .284 & .115 & .018 & .921 & .269 & .137 \\
\hline 60 & 32 & .307 & .088 & .000 & .996 & .297 & .099 \\
\hline 70 & 32 & .091 & .620 & -.096 & .599 & .010 & .958 \\
\hline 80 & 32 & -.179 & .327 & -.245 & .176 & -.180 & .325 \\
\hline 90 & 32 & .183 & .315 & -.069 & .707 & .124 & .497 \\
\hline 100 & 32 & .060 & .744 & -.005 & .976 & .091 & .622 \\
\hline
\end{tabular}

$\mathrm{p}>0.05$

According to table 3, there is no significant correlation between 5 meters sprint duration and velocity parameters of propulsive phase for full SQ exercise performed at different loads of $1 \mathrm{RM}(\mathrm{p}>$ 0.05).

According to table 4, 30 meters sprint durations had a moderate. Negative and significant correlation with MV parameters $(\mathrm{r}=-.412 ; \mathrm{r}=-.399 . \mathrm{p}<0.05$. respectively) during propulsive phase of full SQ exercise performed at 20 and $90 \%$ loads of $1 \mathrm{RM}$ and PV parameters $(\mathrm{r}=-.402 ; \mathrm{r}=-.370 . \mathrm{p}<0.05$. respectively) during propulsive phase of full SQ exercise performed at 40 and $60 \%$ loads of $1 \mathrm{RM}$.

According to table 5, it was seen that correlation between jump performance and velocity parameters in the full SQ exercise performed at different loads of 1RM was not significant statistically $(p>0.05)$.

\section{DISCUSSION}

In this study, it was determined that MV. MPV and PV values during propulsive phase of full SQ 
exercises performed with different loads of 1RM (between 20 - $100 \%$ ) decreased in parallel with load increase. These results were similar to results in literature. According to relationship between strength and muscle contraction velocity expressed in studies completed by Hill at years between 1930 and 1940, there is a negative relationship between strength and contraction velocity. That is load increase cause to increase muscle strength and reduction movement velocity (8). In other words, it could be said that movement velocity during bench press (BP) exercise performed with loads at $50 \%$ of $1 \mathrm{RM}$ was higher than movement velocity of $\mathrm{BP}$ exercise performed with maximum load (1RM) (24). There was a negative relationship between external resistances or loads and concentric contraction velocity of a muscle. If strength (load) implemented at exercise is equal to zero, contraction velocity of muscle will be the highest. However, increase to maximum level of strength implemented at exercise reduces contraction velocity towards zero value (4).

Rahmani et al. (32) determined that load increase at squat exercise performed with different 1RM loads decreased velocity of movement. Also, similar results were found by other researchers. In a study executed by Turner et al. (40) it was obtained that elite rugby players reached to maximum movement velocity at load performed with $20 \%$ of 1RM. this movement velocity was considerably higher than movement velocities obtained with different loads of 1RM and load increases caused to a reduction of movement velocity. In a study using different loads (between $30-80 \%$ of 1RM) and different $\mathrm{BP}$ techniques were revealed that $\mathrm{PV}$ values differentiated according to load values and load increase reduced PV value (12). Cormie et al. (9) determined that velocity of movement performed with load at $0 \%$ of $1 \mathrm{RM}$ value was maximum and this velocity was higher than velocities obtained with loads at $\% 27,42,56,71$ and 85 of 1 RM.

Pearson et al. (30) reported that MPV values obtained in the bench pull exercise was higher than MPV values of BP exercise during movement performed with loads at \%10, 20, 30, 40, 50, 60, 70, 80,90 and 100 of $1 \mathrm{RM}$ value. Also, it was seen that MPV values in the bench press and bench pull exercises were different at same relative load values. The mentioned study, it was obtained that MPV values for BP and bench pull exercises was 0.95 \pm $0.14 \mathrm{~m} / \mathrm{sec} .-1,1.20 \pm 0.16 \mathrm{~m} / \mathrm{sec}$ - -1 , respectively. MPV values of BP and bench pull exercises reduced gradually by load increase. MPV values of BP and bench pull exercises reached with $1 R M$ load were
$0.09 \pm 0.03$ m.sec. -1 and $0.47 \pm 0.03$ m.sec. -1 at this study, respectively.

Similarly, in a study using BP and prone bench pull (PBP) exercises. Sanchez-Medina et al. (37) determined that MPV values in the PBP exercise reached different percentages of 1RM load value (between 30 - $100 \%$ with $5 \%$ load increase) was significantly higher than MPV values in the BP exercise. In addition, MPV values in the some relative load among two exercises were differentiated statistically. The mentioned study, it was obtained that MPV values for both BP and PBP exercises during lifting performed in $30 \%$ of $1 \mathrm{RM}$ load values were $1.29 \pm 0.08 \mathrm{~m} . \mathrm{sec} .-1$ and $1.50 \pm 0.11$ m.sec.-1, respectively. Also, MPV values for $1 \mathrm{RM}$ load of BP and PBP exercises were $0.17 \pm 0.04 \mathrm{~m}$.sec.$1,0.52 \pm 0.05$ m.sec.-1, respectively. When increasing the load for BP and PBP exercise. MPV values decreases. When compared to $\mathrm{BP}$ exercise, the reason of higher movement velocity for PBP exercise was different skeleton muscle structure and different mechanical levers during contrary movements of pushing and drawing. That is longitudinal fiber arrangement and long fibers of active muscles during prone bench pull exercise developed shortening velocity of muscle rapidly. On the other hand, fibers of active muscles during BP exercise were short and these muscle fibers had pennation angles and power production ability (25. 30).

In a another study completed by SanchezMedina et al. (35) obtained that MV values determined with 1RM load in the full SQ exercise was $0.34 \pm 0.05$ m.s- 1 . Gonzales-Badillo and SanchezMedina (18) found that movement velocities in exercises performed with different percentages of $1 \mathrm{RM}$ load value (exercises performed with \% 5 load increase from 30 to $100 \%$ ) were among $0.07 \mathrm{~m} / \mathrm{sec} .-1$ and $0.09 \mathrm{~m} / \mathrm{sec} .-1$. The mentioned study, it was found that mean velocity value during BP exercise performed with $1 \mathrm{RM}$ load was $0.16 \mathrm{~m} / \mathrm{sec} .-1$. low and significant correlation was seen between mean test velocity and velocity of exercise performed with 1RM load.

In this study, it was obtained that there are no statistically significant correlation between MV. MPV and PV values during propulsive phase of full squat movement performed with different loads and 5 meters sprint duration. However it was determined a moderate and negative correlation between 30 meters sprint time and MV values attained at $20 \%$ and $90 \%$ of $1 \mathrm{RM}$ with PV values 
attained at $40 \%$ and $60 \%$ of 1RM. When literature was viewed, it was seen that there are no study researching relationship between velocity parameters during propulsive phase of full squat exercise and sprint performance. Therefore, it was believed that results of this study were important in terms of literature.

In a study researching relationships between vertical jump strength metrics and 5 meters sprint times of amateur athletes whose events were different by Marques et al. (26). it was determined that there are no considerably significant correlation between 5 meter sprint performance with MPV and PV values during countermovement jump exercise practiced by using Smith machine. When mentioned study was viewed. it was seen that this study was researched relationships between 5 meters sprint times and velocity parameters during propulsive phase of countermovement jump and accordingly method of this study was different from method of our study. Even so, no statistically significant correlation between 5 meters sprint time with MV, MPV and PV parameters during propulsive phase of full SQ exercise performed with different loads of $1 R M$ was determined in our study and for this reason. Our study was similar to study of Marques et al. (26) in this regard. According to this result, it was suggested that even if methods of both studies were different. No statistically a significant correlation between 5 meters duration time and velocity parameters. Accordingly, it could be said that time of short distance runs as 5 meters run related to explosiveness ability rather than velocity.

The late studies were focused to determine the best indicator of jump performance. In studies, relationship between jump height and power parameters was investigated $(2,27,33)$ but relationship between jump height and velocity parameters was not investigated. Therefore, conclusions of current study important in terms of completion of lack information at literature. No significant correlation between jump performance and MV, MPV, PV values during propulsive phase of full back squat exercise performed with different loads of 1 RM was obtained in this study.

Consequently, current study is first study investigated relationships among short sprint, jump performance and MV, MPV, PV parameters during propulsive phase of full back squat exercise evaluated by a velocity transducer. Therefore, it could be said that results gotten in this study was too important in terms of completion of available deficiency at literature. In current study, it was seen that MV. MPV and PV values during propulsive phase of full back SQ movement performed with different loads decreased in parallel with increase of load, maximum velocity values for all parameters were gotten during exercises performed with $20 \%$ load of 1RM and minimum velocity values for all parameters were gotten during exercises performed with 1RM load. No statistically a significant correlation among 5 meters sprint times, vertical jump performance and MV, MPV, PV values during propulsive phase of full back squat exercise performed with different 1RM loads was determined. On the contrary, it was obtained that there are moderate negative and significant relationship between 30 meters sprint durations. MV parameter during propulsive phase of full back squat exercise performed with 20 and $90 \%$ of $1 \mathrm{RM}$ and PV parameter during propulsive phase of full back SQ exercise performed with 40 and $60 \%$ of 1RM. In terms of MPV parameter, significant correlation was not seen.

\section{REFERENCES}

1. Aşçı A. Çabuk kuvvet gelişiminde kuvvet eşiğinin belirlenmesi (doktora tezi). Hacettepe Üniversitesi. Ankara. 2001.

2. Ashley CD. Weiss LW. Vertical jump performance and selected physiological characteristics of women. Journal of Strength and Conditioning Research, 1994; 8(1). 5-11.

3. Baker D, Nance S. The relation between strength and power in professional rugby league players. Journal of Strength and Conditioning Research, 1999; 13(3): 224-229.

4. Bartlett R. Introduction to sports biomechanic: Analysing human movement patterns 2nd ed. Oxon: Routledge. 2007.

5. Baughman $M$, Takaha M, Tellez T. Sprint training. National Strength and Conditioning Association. 1984; 6(3): 34-36.

6. Beachle TR, Earle RW, Wathen D. Resistance training. In Essentials of strength training and conditioning. 3rd ed., Beachle TR and Earle RW, eds., United States: Human Kinetics. 2008. 381-412.

7. Bird SP. Tarpenning KM. Marino FE. Designing resistance training programmes to enhance muscular fitness. A review of the acute programme variables. Sports Medicine, 2005; 35(10): 841-851.

8. Boreham C. The physiology of sprint and power training. In The physiology of training: Advances in sport and exercise science series. Whyte G. Eds. Philadelphia: Churchill Livingstone Elsevier. 2006: 117-134.

9. Cormie P. McCaulley GO. Triplett NT. McBride JM. Optimal loading for maximal power output during lower body resistance exercises. Medicine and Science in Sports and Exercise, 2007; 39(2): 340-349.

10. Cormie P. McGuigan MR. Newton RU. Developing maximal neuromuscular power: Part 2 - training considerations for 
improving maximal power production. Sports Medicine, 2011; 41(2): 125-146.

11. Crewther B. Cronin J. Koegh J. Possible stimuli for strength and power adaptation: Acute mechanical responses. Sports Medicine, 2006; 36(1): 65-78.

12. Cronin JB. McNair PJ. Marshall RN. Developing explosive power: A comparison of technique and training. Journal of Science and Medicine in Sport, 2001; 4(1): 59-70.

13. Delecluse C. Van-Coppenolle H. Williams E. Van-Leemputte M. Diels R. Goris M. Influence of high resistance and high velocity training on sprint performance. Medicine and Science in Sports and Exercise, 1995; 27(8): 1203-1209.

14. Earle RW. Beachle TR. Resistance training and spotting techniques. In Essentials of strength training and conditioning. 3rd ed., Beachle TR and Earle RW, Eds. United States: Human Kinetics. 2008. 325-376.

15. Edman KAP, Elzinga G. Noble MIM. Enhancement of mechanical performance by stretch during tetanic contractions of vertebrate skeletal muscle fibres. The Journal of Physiology. 1978; 281: 139-155.

16. Fry AC. The role of resistance exercise intensity on muscle fiber adaptations. Sports Medicine, 2004; 34(10): 663-679.

17. Gabbett TJ, Johns J, Riemann M. Performance changes following training in junior rugby league players. Journal of Strength and Conditioning Research, 2008; 22(3): 910-917.

18. Gonzales-Badillo JJ. Sanchez-Medina L. Movement velocity as a measure of loading intensity in resistance training. International Journal of Sports Medicine, 2010; 31(5): 347-352.

19. Gonzales-Badillo JJ, Marques MC, Sanchez-Medina L. The importance of movement velocity as a measure to control resistance training intensity. Journal of Human Kinetics (Special Issue), 2011; 29A. 15-19.

20. Izquierdo M, Gonzales-Badillo JJ, Hakkinen H, Ibanez J, Kraemer WJ, Altadill A, Eslava J, Gorostiaga EM. Effect of loading on unintentional lifting velocity declines during single sets of repetition to failure during upper and lower extremity muscle actions. International Journal of Sports Medicine, 2006; 27(9): 718-724.

21. Kawamori N, Newton RU. Velocity specificity of resistance training: Actual movement velocity versus intention to move explosively. Strength and Conditioning Journal, 2006; 28(2): 86-91.

22. Kraemer WJ, Fleck SJ, Deschenes M. A review: Factors in exercise prescription of resistance training Strength and Conditioning Journal, 1988; 10(5): 36-42.

23. Kraemer WJ, Ratamess RA. Fundamentals of resistance training: progression and exercise prescription. Medicine Sciences and Sports Exercise, 2004; 36(4): 674-688.

24. Kraemer JW, Vinger LJ. Muscle anatomy. In Strength training: National strength and conditioning association. Brown EL. Eds. United States: Human Kinetics. 2007. 3-28.

25. Lieber RL, Friden J. Functional and clinical significance of skeletal muscle architecture. Muscle Nerve, 2000; 23(11): 16471666.

26. Marques MC, Gil H, Ramos R, Costa AM, Marinho DA. Relationship between vertical jump strength metrics and 5 meters sprint times. Journal of Human Kinetics, 2011; 29: 115122.
27. Marques MC, Gonzales-Badillo JJ. Relationship between strength parameters and squat jump performance in trained athletes. Journal Motricidade, 2011; 7(4): 43-48.

28. Pareja-Blanco F, Sanchez-Medina L, Suarez-Arrones L, Gonzales-Badillo JJ. Resistance training with lower velocity loss within a set produces greater strength. $16^{\text {th }}$ Annual Congress of the ECSS. 6-9 July. Liverpool. UK. 2011.

29. Pareja-Blanco F, Rodriguez-Rosell D, Sanchez-Medina L, Gorostiaga EM, Gonzales-Badillo JJ. Effect of movement velocity during resistance training on neuromuscular performance. International Journal of Sports Medicine, 2014; 35(11): 1-9.

30. Pearson SN, Cronin JB, Hume PA, Slyfield D. Kinematics and kinetics of the bench press and bench pull exercises in a strength-trained sporting population. Sports Biomechanics, 2009; 8(3): 245-254.

31. Pereira MIR, Gomes PSC. Movement velocity in resistance training. Sports Medicine, 2003; 33(6): 427-438.

32. Rahmani A, Viale F, Dalleau G, Lacour JR. Force / velocity and power / velocity relationship in squat exercise. European Journal of Applied Physiology, 2001; 84(3): 227-232.

33. Requena B, Gonzales-Badillo JJ, Villareal ESS, Ereline J, Garcia I, Gapeyeva H, Paasuke M. Functional performance maximal strength and power characteristics in isometric and dynamic actions of lower extremities in soccer players. Journal of Strength and Conditioning Research, 2009; 23(5): 1391-1401.

34. Sanchez-Medina L, Perez CE, Gonzales-Badillo JJ. Importance of the propulsive phase in strength assessment. International Journal of Sports Medicine, 2010; 31(2): 123-129.

35. Sanchez-Medina L, Garcia-Pallares J, Perez CE, Fernandes J, Gonzales-Badillo JJ. Estimation of relative load from mean velocity in the full squat exercise. $16^{\text {th }}$ Annual Congress of the ECSS. 6-9 July. Liverpool. UK. 2011.

36. Sanchez-Medina L, Gonzales-Badillo JJ. Velocity loss as an indicator of neuromuscular fatigue during resistance training. Medicine and Science in Sports and Exercise, 2011; 43(9): 1725-1734.

37. Sanchez-Medina L, Gonzales-Badillo JJ, Perez CE, GarciaPallares J. Velocity and power - load relationship of the bench pull vs. bench press exercises. International Journal of Sports Medicine, 2014; 35(3): 209-216.

38. Santos EJAM, Janeira MAAS. Effects of complex training on explosive strength in adolescent male basketball players. Journal of Strength and Conditioning Research, 2008; 22(3): 903-909.

39. Spiering BA, Kraemer WJ, Anderson JM, Armstrong LE, Nindl BC, Volek JS, Maresh CM. Resistance exercise biology. Manipulation of resistance exercise programme variables determines the responses of cellular and molecular signaling pathways. Sports Medicine, 2008; 38: 527-540

40. Turner AP, Unholz CN, Potts N, Coleman SGS. Peak power, force and velocity during jump squats in professional rugby players. Journal of Strength and Conditioning Research, 2012; 26(6): 1594-1600.

41. Zatsiorsky VM. Kinematics of human motion. United States: Human Kinetics. 1998. 